\title{
Combination of Huanglian Jiedu Decoction and erlotinib delays growth and improves sensitivity of EGFR-mutated NSCLC cells in vitro and in vivo via STAT3/Bcl-2 signaling
}

\author{
XIAOWEN ZHOU ${ }^{1 *}$, BOJIA LIU ${ }^{1,2^{*}}$, QING NING $^{2}$, ZHI XIA ${ }^{2}$, RONGLING ZHONG ${ }^{2}$, LI ZHANG $^{2}$ and LEI WU $^{1}$ \\ ${ }^{1}$ Department of Pharmacy, Jiangsu Province Hospital of Chinese Medicine, \\ Affiliated Hospital of Nanjing University of Chinese Medicine, Nanjing, \\ Jiangsu 210036; ${ }^{2}$ Key Laboratory of Delivery Systems of Chinese Meteria Medica, \\ Affiliated Hospital of Integrated Traditional Chinese and Western Medicine, \\ Nanjing University of Chinese Medicine, Nanjing, Jiangsu 210028, P.R. China
}

Received July 5, 2020; Accepted October 6, 2020

DOI: $10.3892 /$ or.2020.7848

\begin{abstract}
Erlotinib, an epidermal growth factor receptor (EGFR) tyrosine kinase inhibitor (TKI), is widely used in the treatment of non-small cell lung cancer (NSCLC). However, erlotinib resistance leads to high mortality in patients with NSCLC, while the activation of STAT3 is closely related to erlotinib resistance. Studies have shown that the main components of Huanglian Jiedu Decoction (HJD) have antitumor effects. Therefore, the anticancer effect of HJD combined with erlotinib on NSCLC cells was investigated. The NSCLC HCC827, HCC827ER, and H1975 cell lines as well as xenograft nude mice were selected as models to study the effects of HJD. The proapoptotic effects of HJD were examined by CCK-8 and apoptosis assays. ELISA, immunostaining, and western blot analysis were also performed. HJD considerably enhanced the anticancer effect of erlotinib in both EGFR-TKI-resistant
\end{abstract}

Correspondence to: Dr Rongling Zhong, Key Laboratory of Delivery Systems of Chinese Meteria Medica, Affiliated Hospital of Integrated Traditional Chinese and Western Medicine, Nanjing University of Chinese Medicine, 100 Shizi Street, Hongshan Road, Nanjing, Jiangsu 210028, P.R. China

E-mail: zhongronglingpham@163.com

Dr Lei Wu, Department of Pharmacy, Jiangsu Province Hospital of Chinese Medicine, Affiliated Hospital of Nanjing University of Chinese Medicine, Nanjing, Jiangsu 210036, P.R. China

E-mail: xiaoleiyaoshi@163.com

${ }^{*}$ Contributed equally

Abbreviations: SDC, Shuangdan capsule; EGFR, epidermal growth factor receptor; TKI, tyrosine kinase inhibitors; NSCLC, non-small cell lung cancer; HCC827ER, erlotinib-resistant HCC827 cell line; FBS, fetal bovine serum

Key words: Huanglian Jiedu decoction, erlotinib, NSCLC cells, STAT3, EGFR and -sensitive NSCLC cells. HJD promoted erlotinib-induced apoptosis and caspase 3 activity. The co-treatment also inhibited the expression of $\mathrm{Bcl}-\mathrm{XL}, \mathrm{Bcl}-2$, and p-STAT3. In addition, siSTAT3 had similar functions with HJD. In particular, the apoptotic rates of erlotinib-stimulated HCC827, HCC827ER, and H1975 cells were enhanced by transfecting siSTAT3. Furthermore, overexpression of STAT3 significantly inhibited HJD-mediated erlotinib sensitization. The combined use of HJD with erlotinib significantly reduced tumor growth in erlotinib-resistant HCC827ER and H1975 xenografts, induced caspase 3, and inhibited Ki67, STAT3, and Bcl-2 expression. HJD significantly alleviated erlotinib resistance by regulating the STAT3/Bcl-2 signaling pathway, which is a promising method to overcome the EGFR-TKI resistance of NSCLC.

\section{Introduction}

Lung cancer is one of the most frequently diagnosed malignant tumors and almost $80-85 \%$ of lung cancer is non-small cell lung cancer (NSCLC). Primary lung cancer is the leading cause of cancer-related death worldwide $(1,2)$. Lung cancer is complemented with a high rate of mortality and is often not diagnosed until reaching a late stage. With advances in many aspects of the treatment, diagnosis, and classification, the overall survival of NSCLC patients at early-stage NSCLC has improved after complete resection. However, postoperative recurrence and metastasis are also major obstacles to prolonged survival in early-stage NSCLC (3-5). Even though conventional chemotherapy has favorable therapeutic effects, the side effects of the drugs that influence the life quality of patients greatly limit the application. As drug resistance is commonly seen with NSCLC cases, more effective treatment strategies should be explored.

The epidermal growth factor receptor (EGFR), a member of the transmembrane receptor tyrosine kinases of the ErbB family, is involved in the regulation of signal pathways, including proliferation, metastasis, epithelial-mesenchymal transformation, and apoptosis. Gefitinib (Iressa) and erlotinib (Tarceva) are two US FDA-approved EGFR-specific tyrosine 
kinase inhibitors (TKIs) that have exhibited clinical benefit in treating NSCLC $(6,7)$. Erlotinib treatment prolonged the progression-free survival of NSCLC patients, who harbor EGFR exon 19 deletion or L858R mutations (EGFR Mut+ NSCLC) (8). However, almost all tumors eventually develop acquired resistance to the treatment, with $50 \%$ of the patients developing EGFR T790M resistance mutations (9). Several mechanisms of EGFR-TKI resistance have been reported, including EGFR T790M mutation and MET amplification. Overactivation of several protein kinases, such as signal transducer and activator of transcription 3 (STAT3), has been reported to be one of the causes of drug resistance in NSCLC (10). HCC827 cells carry the erlotinib-sensitive mutation (E746-A750 deletion), but not the drug-resistant mutation (T790M) (11). Subsequently, HCC827 cells are sensitive to erlotinib and other EGFR-TKIs (12). Interestingly, compared with HCC827 cells, erlotinib-resistant HCC827 cells (HCC827ER) showed higher levels of pSTAT3 (13). Erlotinib also induces resistance in PC-9 cells by activating STAT3 (14). In addition, HCC827ER cells showed greater invasiveness in Matrigel-coated Boyden chambers than the parental HCC827 cell line (15). H1975 is a human adenocarcinoma cell line with the EGFR T790M/L858R mutation that is regarded as an EGFR-TKI acquired drug-resistant cell line (16).

Huanglian Jiedu Decoction (HJD) is one of the traditional Chinese medicines used to treat diabetes in ancient China. It is known for its liver protective effects, including liver detoxification (17). It was first recorded in Wai-tai-mi-yao (Arcane Essentials from the Imperial Library) written by Wang Tao of the Tang dynasty and widely used in clinical practice (18). The main active components of HLD are known to have antitumor effects. For example, baicalin and baicalein can reduce STAT3 activity, further downregulate the expression of IFN- $\gamma$-induced PD-L1, and then restore the sensitivity of T cells to kill tumor cells (19). Berberine hydrochloride can inhibit the proliferation of cervical cancer cells HeLa229 and induce apoptosis by upregulating p53 and downregulating the expression levels of Bcl-2 and COX-2 mRNA (20). Baicalin inhibits cell growth of SW1353 by downregulating Bcl-2 and activating caspase-3 and -9 (21). In addition, wogonin (5,7-dihydroxy-8-methoxyflavone) (an O-methylated flavone) inhibited tumor proliferation in Raji xenograft mice by decreasing the expression of Ki67 (22). Therefore, we hypothesized that the STAT3/Bcl-2 signaling pathway and its downstream targets may be involved in the antitumor effect of HJD.

As erlotinib and HJD act via two different pathways key to tumor growth, using these drugs concurrently may confer promising clinical benefits to NSCLC patients. The aim of this study was to discuss the potential of combined inhibition in clinically relevant xenograft models of EGFR TKI resistance and to explore whether dual blockade may provide a significant advantage over monotherapy.

\section{Materials and methods}

Preparation and HPLC analysis of HJD. The herbal materials of HJD composed of Fructus gardeniae (90 g), Cortex phellodendri (60 g), Radix scutellariae (60 g), and Rhizoma coptidis $(90 \mathrm{~g})$. The herbs were all purchased from Ma'anshan
Jingquan Traditional Chinese Medicine Decoction pieces, Co., Ltd. The authenticity of the plant species was confirmed by Dr Huang Yawei from Ma'anshan Jingquan Traditional Chinese Medicine Decoction pieces Co., Ltd. HJD was refluxed with water $(1: 10, w / v)$ for $2 \mathrm{~h}$. Afterwards, the HJD extract was obtained by drying the concentrate with vacuum concentration. Powered HJD samples were sonicated with methanol for $1 \mathrm{~h}$. The sample was finally filtrated through a $0.45 \mu \mathrm{M}$ membrane filter prior to HPLC analysis. The separation was performed on a Waters Acquity C18 column (250x4.6 mm, $5 \mu \mathrm{m})$. Separation was carried out by acetonitrile (A) and $0.05 \% \mathrm{~K}_{2} \mathrm{HPO}_{4}$ and $0.05 \%$ triethanolamine in water (B). The linear gradient elution was $82 \% \mathrm{~A}$, in $0-9 \mathrm{~min} ; 82-73 \% \mathrm{~A}$, in 9-27 $\mathrm{min}$; $73-60 \% \mathrm{~A}$, in $27-45 \mathrm{~min}$; $60-82 \% \mathrm{~A}$, in $45-60 \mathrm{~min}$ with a flow rate of $1.0 \mathrm{ml} / \mathrm{min}$. The UV detection was operated at $254 \mathrm{~nm}$, and the injection volume was $20 \mu \mathrm{l}$. The external standard method was applied for the identification by comparing their retention time and spectrum against known standards (Fig. 1 and Table I).

Cell culture and reagents. The NSCLC HCC827, A549, H460, and H1975 cell lines were obtained from the American Type Culture Collection (Manassas). Cell lines were maintained in DMEM medium supplemented with $10 \%$ fetal bovine serum (FBS) at $37^{\circ} \mathrm{C}$ with $5 \% \mathrm{CO}_{2}$. The acquired erlotinib-resistant HCC827 cell line (HCC827/ER) was established by exposing erlotinib-sensitive $\mathrm{HCC} 827$ cells to gradually increasing concentrations of erlotinib from 0.1 to $10 \mu \mathrm{M}$ over a 6-month period at $37^{\circ} \mathrm{C}$. Erlotinib was purchased from Selleck (cat. no. S7786). The caspase-3 inhibitor Z-DEVD-FMK was obtained from Gene Operation (cat. no. IAP1201). Stock solution was prepared in dimethyl sulfoxide at $10 \mathrm{mM}$ and was stored at $-20^{\circ} \mathrm{C}$.

Cytotoxicity assay. The Cell Counting Kit-8 (CCK-8) assay was used to determine cell proliferation. Cells $\left(5 \times 10^{4}\right)$ were prepared and mixed evenly, and then $0.1 \mathrm{ml}$ cell suspension was added to each of the 96 -well plates. Cells were cultured in a $5 \% \mathrm{CO}_{2}$ incubator at $37^{\circ} \mathrm{C}$ for $72 \mathrm{~h}$. Subsequently, $10 \mu \mathrm{l}$ CCK-8 solution was added to each well and incubated for $4 \mathrm{~h}$ (in the dark). Cell proliferation was evaluated by using FLUOstar ${ }^{\circledR}$ Omega microplate reader to measure the absorbance of cells at the wavelength of $450 \mathrm{~nm}$.

Detection of cell apoptosis by flow cytometry. Apoptosis was detected using the apoptosis detection kit (Biosea Biotechnology). The HCC827, H1975 and HCC827ER cells were separately inoculated on a 6-well plate and cultured in complete medium for $72 \mathrm{~h}$, then treated with DMSO (control), HJD only, erlotinib only, and HJD+E, respectively. The cells were collected, washed twice in cold PBS, then stained with Annexin $\mathrm{V}$ and propyl iodide (PI). The stained cells were collected and analyzed by flow cytometry. FlowJo software was used to analyze the results.

Caspase-3/7 activity assay. Caspase- $3 / 7$ activity was measured by the Apo-One homogeneous caspase-3/7 Assay kit (Promega, no. G7790). Then, $1 \times 10^{4}$ cells per well were inoculated, incubated for $24 \mathrm{~h}$ and then treated with HJD, erlotinib and HJD+E, respectively, for $72 \mathrm{~h}$. The cells were 

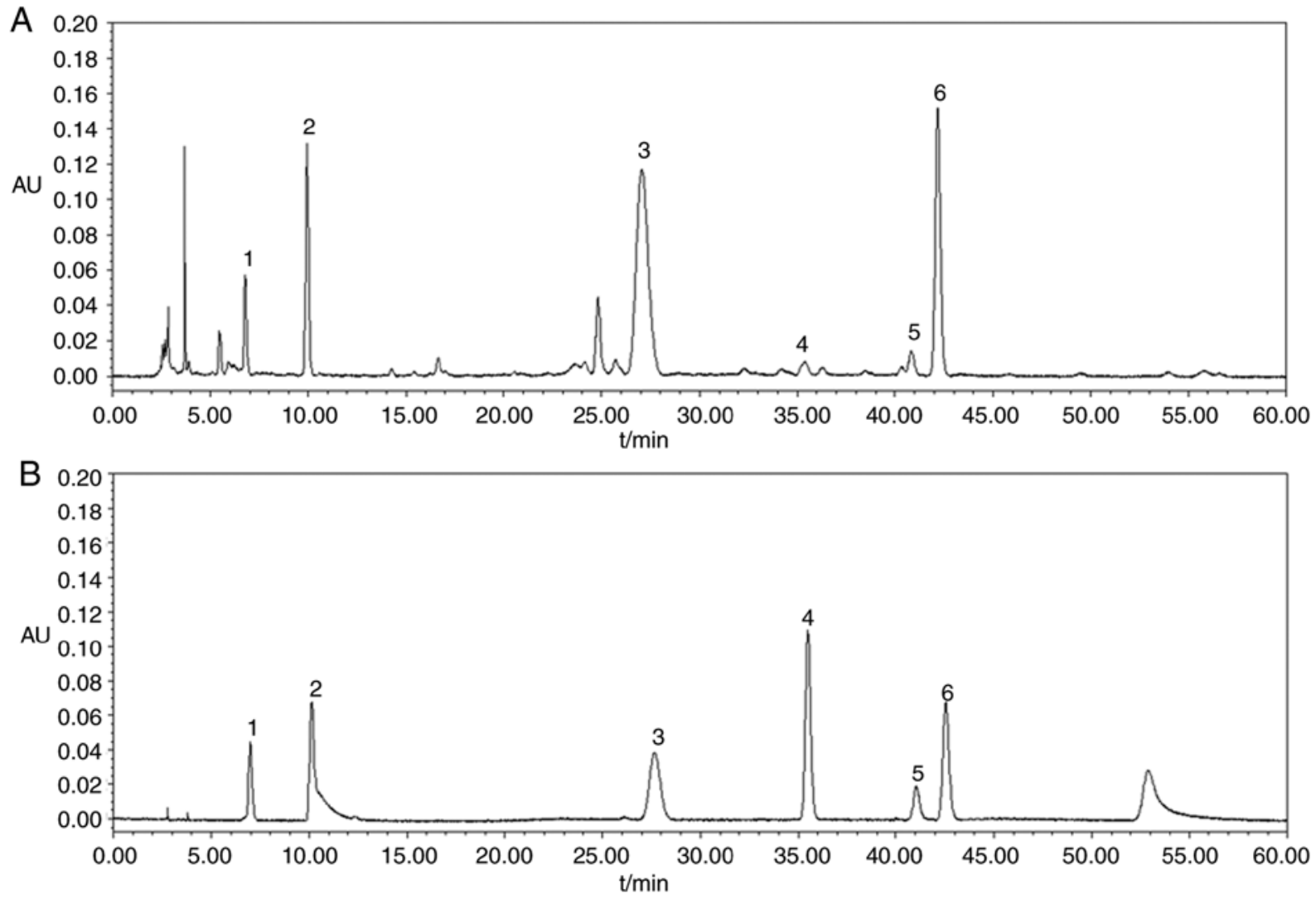

Figure 1. HPLC chromatograms of (A) HJD extracts and (B) standards. Peaks: 1, geniposide; 2, baicalin; 3, berberine hydrochloride; 4, wogonoside; 5, baicalein; 6 , wogonin.

then washed with PBS three times. The activity of caspase-3/7 was evaluated according to the manufacturer's instructions.

Cell lysates preparation and immunoblotting. The cells were mixed with RIPA lysis buffer to extract total protein. The protein concentration was measured by bicinchoninic acid (BCA) method. Then protein samples $(50 \mu \mathrm{g})$ were subjected to $10 \%$ SDS-PAGE gel electrophoresis and transferred to PVDF membranes. Subsequently, PVDF membranes were blocked in 5\% skimmed milk for $1 \mathrm{~h}$ at room temperature and then incubated with primary antibody overnight at $4^{\circ} \mathrm{C}$. Cleaved-caspase 3 (cat. no. ab49822, 1:1,000), p-STAT3 (cat.no. ab76315, 1:3,000), t-STAT3 (cat. no. ab68153, 1:2,000), Bcl-2 (cat. no. ab182858, 1:2,000), Bcl-XL (cat. no. ab32370, 1:1,000), GAPDH (cat. no. ab8245, 1:5,000), p-STAT1 (cat. no. ab109461, 1:3,000), t-STAT1 (cat. no. ab180814, 1:1,000), p-STAT2 (cat. no. ab53132, 1:3,000), t-STAT2 (cat. no. ab32367, 1:2,000), p-STAT5 (cat. no. ab32364, 1:2,000), t-STAT5 (cat. no. ab32364, 1:1,000) were purchased from Abcam. Next day, the membranes were incubated with horseradish peroxidase-conjugated goat anti-rabbit IgG H\&L (cat. no. ab205718; 1:6,000, Abcam) or goat anti-rat IgG H\&L (cat. no. ab97057; 1:5,000, Abcam) secondary antibodies at room temperature for $2 \mathrm{~h}$. Finally, the protein bands were detected using the Tanon-5200 Multi chemiluminescent gel imaging system.

In vivo study protocol. Six-week-old male nude mice were purchased from the Model Animal Reasearch Center of
Nanjing University (Nanjing, China). Twenty-four mice (22 g) were maintained in a specific pathogen-free environment with a 12-h light/dark cycle and fed with standard food and water ad libitum. This study and the animal experimental protocols were approved by the Institutional Animal Care and Use Committee of Jiangsu Provincial Academy of Chinese Medicine.

Approximately $5 \times 10^{6} \mathrm{HCC} 827 / \mathrm{ER}$ cells or $\mathrm{H} 1975$ cells were suspended in $0.2 \mathrm{ml}$ DMEM medium and injected subcutaneously into the right flank region of nude mice, respectively. When the average tumor size reached $\sim 75 \mathrm{~mm}^{3}$, the mice were randomized into four groups ( $n=6$ each): i) Vehicle group, ii) HJD group $(50 \mathrm{mg} / \mathrm{kg})$, iii) erlotinib group $(20 \mathrm{mg} / \mathrm{kg})$, iv) combination of HJD $(50 \mathrm{mg} / \mathrm{kg})$ and erlotinib $(20 \mathrm{mg} / \mathrm{kg})$. All of the treatments were orally administrated once a day for 27 consecutive days. The formula, 1/2(length $\mathrm{x}$ width ${ }^{2}$ ), was used to estimate tumor sizes. The body weight and the tumor volume (V) were recorded every 3 days. At the end of the experiment, the mice were sacrificed by manual cervical dislocation, which resulted in euthanasia within approximately $10 \mathrm{sec}$. The tumors were then dissected and weighed to calculate the inhibitory rate.

The animal experiments were approved by the ethics committee of the Affiliated Hospital of Integrated Traditional Chinese and Western Medicine (Nanjing, China).

Immunohistochemistry. Tissues were collected and fixed in $10 \%$ formalin for $24 \mathrm{~h}$ at room temperature, then embedded in paraffin, and sectioned. The tissue sections $(5 \mu \mathrm{m})$ were 
Table I. The structure of the standards in HPLC chromatograms of HJD extracts.

\begin{tabular}{llll}
\hline Name & Type & Structures
\end{tabular}

Geniposide

Baicalin

Berberine hydrochloride

Wogonoside

Baicalein

Wogonin

Flavonoids

Flavonoids

Flavonoids

Flavonoids<smiles>COC(=O)C1=COC(OC2OC(CO)C(O)C(O)C2O)C2C(CO)=CCC12</smiles>

Isoquinoline alkaloids<smiles>CC(=O)C1OC(Oc2cc3oc(-c4ccccc4)cc(=O)c3c(O)c2O)C(C)C(C)C1C</smiles><smiles>COc1ccc2cc3c(cc2c1OC)CCc1cc2c(cc1-3)OCO2</smiles><smiles>COc1c(OC2OC(C(=O)O)C(O)C(O)C2(C)C)cc(O)c2c(=O)cc(-c3ccccc3)oc12</smiles><smiles>O=c1cc(-c2ccccc2)oc2cc(O)c(O)c(O)c12</smiles><smiles>COc1c(O)cc(O)c2c(=O)cc(-c3ccccc3)oc12</smiles>

dewaxed, incubated with $3 \%$ methanol-hydrogen peroxide and washed with PBS three times. Sections were placed in citric acid buffer, heated and boiled, and washed with PBS. Then, the sections were blocked with goat serum (cat. no. 7481; Abcam) for $20 \mathrm{~min}$, and incubated with STAT3 and Bcl-2 antibodies at $4^{\circ} \mathrm{C}$ overnight. Next day, the sections were incubated with goat anti-rabbit IgG H\&L (horseradish peroxidase) antibodies (cat. no. ab205718; 1:5,000, Abcam). A 3,3'-diaminobenzidine (DAB) kit was used to observe the specific labeling (brownish yellow staining), and hemotaxylin was used for counterstain cell nuclei (blue staining). Images were obtained from each slide using a digital trinocular microscope (Zeiss Axio Observer A1).
Table II. Mutation profile of NSCLC cell lines.

\begin{tabular}{lll}
\hline Cell lines & \multicolumn{1}{c}{ EGFR gene } & K-Ras gene \\
\hline A549 & WT & G12S \\
H1975 & Exon19 T790M-L858R & WT \\
HCC827 & Exon19 (E746-A750) del & WT \\
HCC827ER & Exon19 (E746-A750) del & WT \\
H460 & WT & G61H \\
\hline
\end{tabular}

$H \& E$ staining. The collected nude mouse tissues were fixed with formalin, paraffin-embedded, cut into $4 \mu \mathrm{m}$ slices, and 

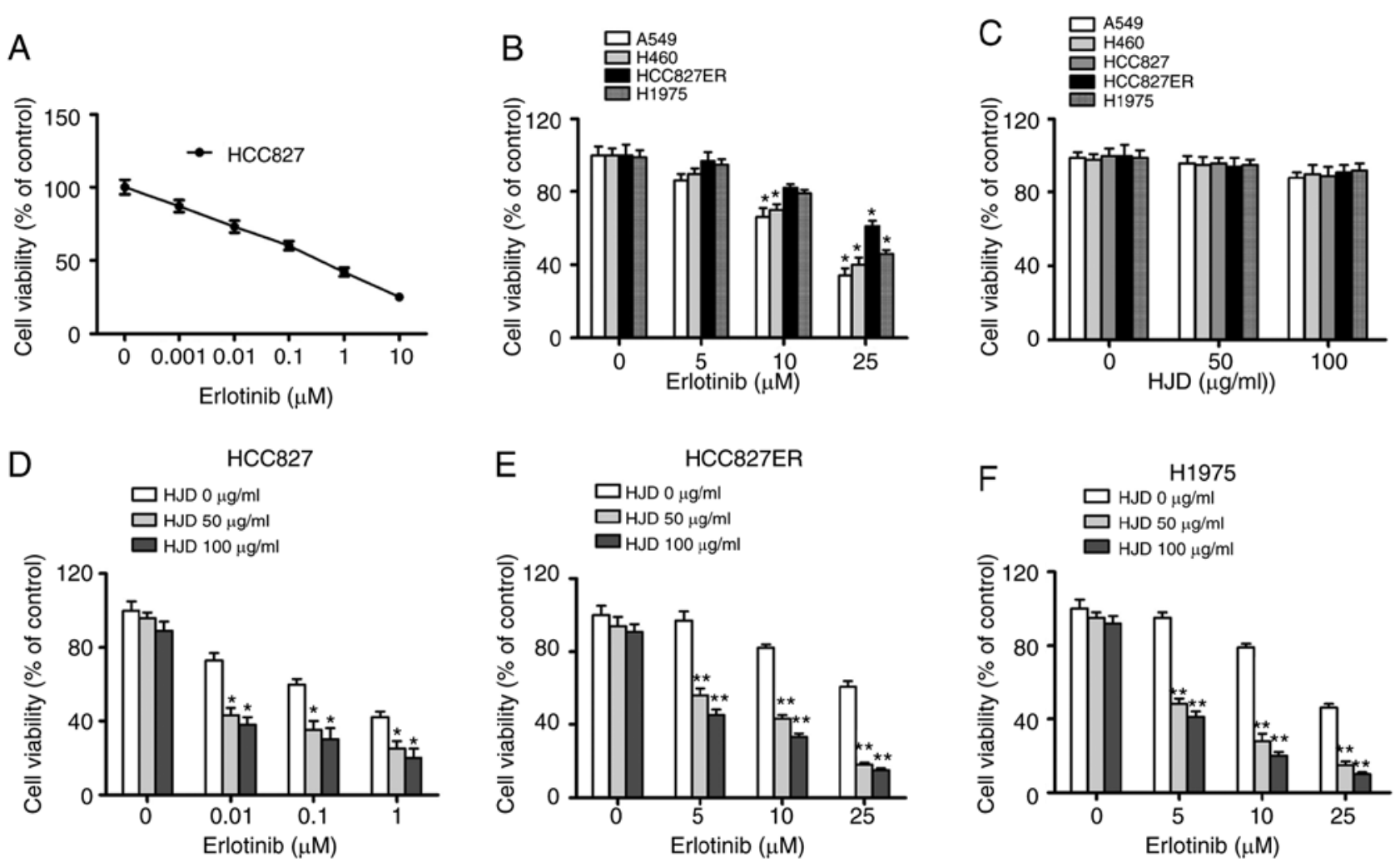

Figure 2. The inhibitory effect of HJD and/or erlotinib on NSCLC cell lines after $72 \mathrm{~h}$ treatment with CCK-8 assays. (A) HCC827 cell viability after erlotinib treatment. (B) Different susceptibility of NSCLC cell lines (A549, H460, H1975 and HCC827ER) to erlotinib after $72 \mathrm{~h}$ treatment. "P<0.05 (vs. control). (C) Viability of NSCLC cell lines after $72 \mathrm{~h}$ treatment of HJD. (D-F) The inhibitory effect of HJD plus erlotinib on HCC827, H1975, and HCC827ER cells after $72 \mathrm{~h}$ treatment. ${ }^{*} \mathrm{P}<0.05$ (vs. erlotinib); ** $\mathrm{P}<0.01$ (vs. erlotinib). Each value represents the mean $\pm \mathrm{SD}$.

roasted in an oven for $3 \mathrm{~h}$. Sections with xylene were first washed three times, then different gradient ethanol $(75,85,95$ and $100 \%$ ) was used to rinse the tissues twice, prior to staining the sections with hematoxylin. Then, sections were immersed in hydrochloric acid-ethanol solution, dyed with ammonia water, and redyed with eosin. Finally, sections were immersed in different gradient of ethanol $(75,85,95$ and 100\%) and sealed with neutral resin.

Statistical analysis. SPSS Statistics version 13.0 was used for all statistical analyses (SPSS Inc.). Statistical comparisons were performed using one-way ANOVA followed by Tukey's multiple comparison post hoc test and $\mathrm{P}<0.05$ was considered statistically different. The results were presented as the mean \pm SD.

\section{Results}

HJD strengthens EGFR-TKI sensitivity and reduces the drug resistance of NSCLC cells to erlotinib. To evaluate whether HJD could overcome the resistance of NSCLC cells to erlotinib, the inhibitory effect of co-treatments on HCC827, HCC827ER, H1975, H460 and A549 cell growth was assessed using a standard CCK- 8 assay. The mutation profile of NSCLC cell lines is shown in Table II. Consistent with earlier studies, cells bearing mutated EGFR (HCC827) were more sensitive to erlotinib than those bearing wild-type EGFR (H460, A549). However, H1975 cells with both L858R and T790M mutations were relatively insensitive to erlotinib treatment. HCC827 erlotinib-resistant cells (HCC827ER) were established by a series of stepwise increase of the erlotinib concentration until HCC827ER was no longer responsive to $5 \mu \mathrm{M}$ erlotinib. HCC827ER cells were more resistant to erlotinib than $\mathrm{HCC} 827$ cells $\left(\mathrm{IC}_{50}=31.26\right.$ vs. $0.11 \mu \mathrm{M})$ (Fig. 2A and B).

To determine whetherHJD can inhibit the growth of NSCLC cells, cell viability was determined. HJD $(0-100 \mu \mathrm{g} / \mathrm{ml})$ did not produce significant toxicity in NSCLC cells, independent of the EGFR-mutated status (Fig. 2C). However, HJD acting on NSCLC cells showed synergistic effects with erlotinib. The combination of HJD $(50 \mu \mathrm{g} / \mathrm{ml})$ with erlotinib led to $57 \%$ inhibition on the ability of HCC827ER cells (Fig. 2D), although erlotinib $(10 \mu \mathrm{M})$ alone exhibited a slight effect ( 20\% inhibition) on cell ability (Fig. 2E). In parallel, the H1975 cell line was also sensitive to the combined administration (Fig. 2F).

HJD amplifies erlotinib-induced apoptosis. Apoptosis is involved in the anticancer effect of erlotinib (23). To measure whether the synergistic effect of HJD on erlotinib was associated with apoptosis, cells were stained with Annexin V-FITC/PI and analyzed using flow cytometry. As shown in Fig. 3A, erlotinib-stimulated apoptosis was significantly enhanced by HJD in H1975, HCC827 and HCC827ER cells (Fig. 3A). As demonstrated in ELISA assays, Caspase-3/7 activation was also significantly induced by combination treatment in these cell lines $(\mathrm{P}<0.05$, Fig. 3B), suggesting that erlotinib-augmented activation of caspase was meaningfully promoted by HJD. Moreover, the caspase-3 inhibitor Z-DEVD-FMK could 
A
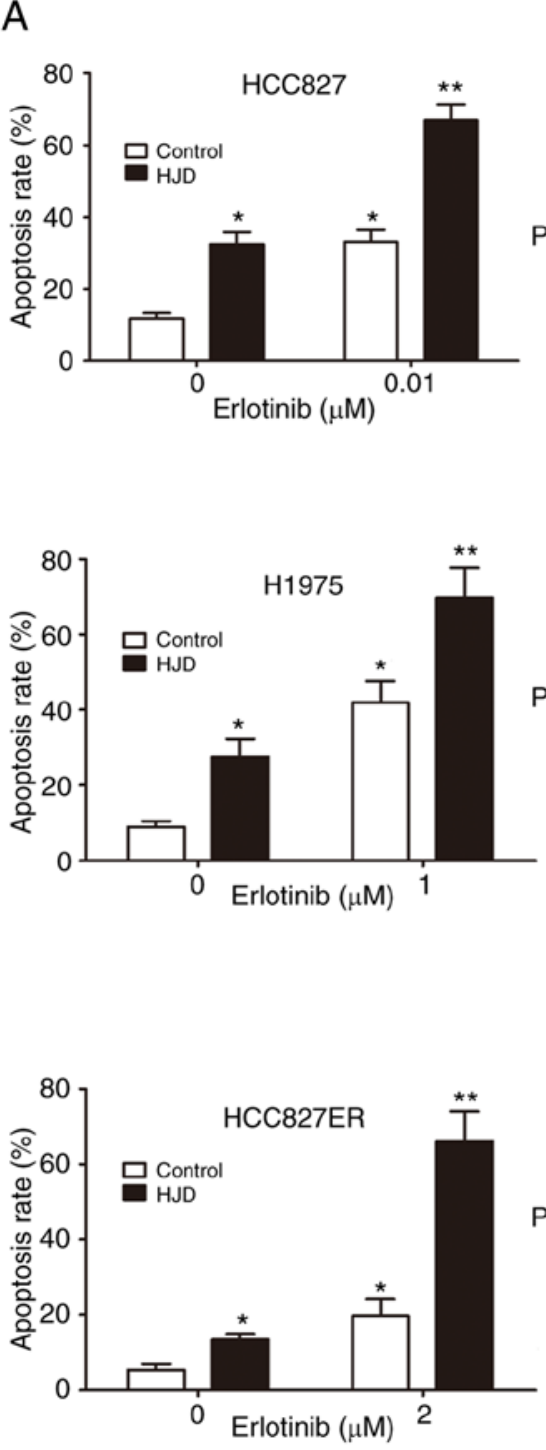
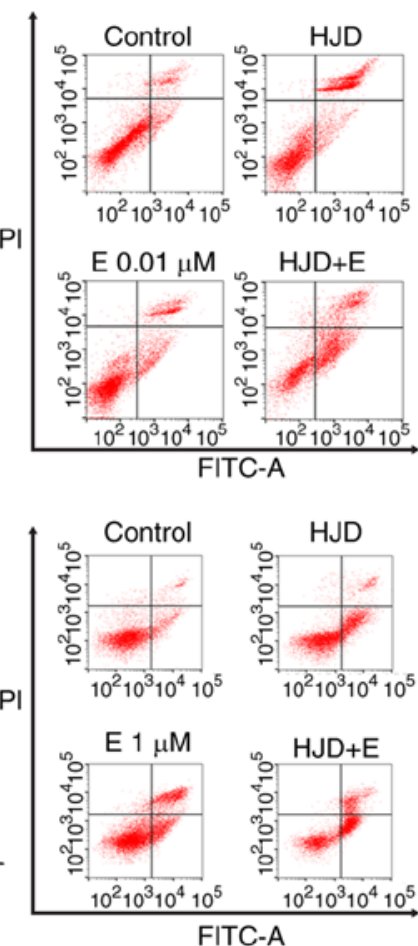

FITC-A

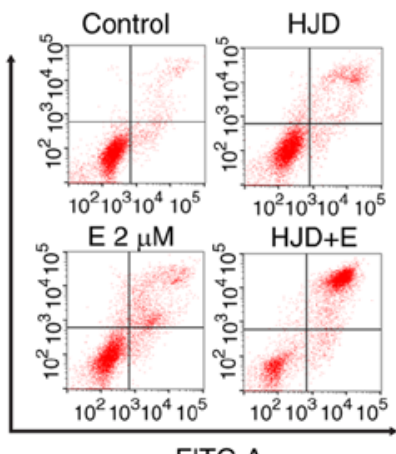

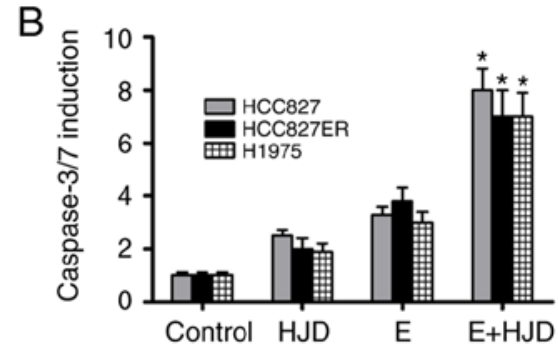

C

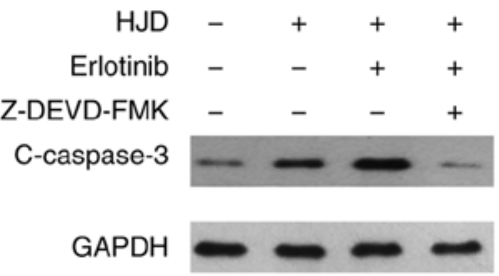

Figure 3. HJD and erlotinib induced apoptosis in NSCLC cells. (A) Representative image for cell apoptosis stained with Annexin V-FITC/PI. HCC827, HCC827ER and H1975 cells processed with HJD, erlotinib, or HJD+E. The cells were then stained with Annexin V-FITC/PI and analyzed by flow cytometry. ${ }^{*} \mathrm{P}<0.05$, ${ }^{* *} \mathrm{P}<0.01$ (vs. erlotinib). Each value represents the mean \pm SD. (B) The effects of HJD, E and HJD+E on caspase-3/7 activity were determined by an ELISA kit. ${ }^{*}<0.05$ (vs. erlotinib). (C) Each value represents the mean \pm SD. The effects of HJD, E and HJD+E on caspase-3 activity evaluated by western blotting.

almost abrogate the activation of caspase 3 caused by HJD (Fig. 3C).

Erlotinib-induced STAT3 activation was inhibited by $H J D$. To better understand the drug resistance mechanism of HCC827ER cells, we carefully analyzed its characteristics. We found that the level of p-STAT3 in erlotinib-sensitive primary HCC 827 cells was much lower than that in HCC827ER cells (Fig. 4A). Abnormal activation of STAT3 in tumor cells ensures the survival of malignant cells under stress conditions and also leads to multi-drug resistance (24). Erlotinib did not reduce the higher levels of STAT3 phosphorylation in HCC827ER cells (Fig. 4B). Therefore, we detected the effect of STAT3 on HJD-mediated erlotinib sensitization. Erlotinib therapy resulted in the feedback activation of STAT3 in H1975 cells (Fig. 4C), consistent with previous studies $(13,25)$. However, HJD significantly inhibited the levels of p-STAT3 and its downstream targets, $\mathrm{Bcl}-2$ and $\mathrm{Bcl}-\mathrm{XL}$ proteins induced by erlotinib, suggesting that STAT3 may be related to HJD-mediated erlotinib sensitizing. In addition, we evaluated other members of the STAT family. The effect of Erlotinib and HJD was independent of the phosphorylation of STAT1, STAT2, and STAT5 (Fig. 4D). Furthermore, HJD did not potentiate the inhibitory effect of erlotinib on EGFR phosphorylation of HCC827ER and H1975 cells (Fig. S1).

To verify the effect of STAT3 on erlotinib resistance, we transfected HCC827, HCC827ER, and H1975 cells with STAT3-specific siRNAs. The effect of siSTAT3 on apoptosis was assessed. The apoptosis rate of HCC827ER cells induced by erlotinib alone was $24.1 \pm 4.4 \%$, and the apoptosis rate increased to $49.1 \pm 5.2 \%$ after siSTAT3 transfection $(\mathrm{P}<0.01)$. A similar increment in erlotinib-induced apoptosis was also observed in both H1975 and HCC827 cells after siSTAT3 transfection (Fig. 5A). siSTAT3 significantly inhibited endogenous STAT3 and enhanced the inhibition of erlotinib 
B
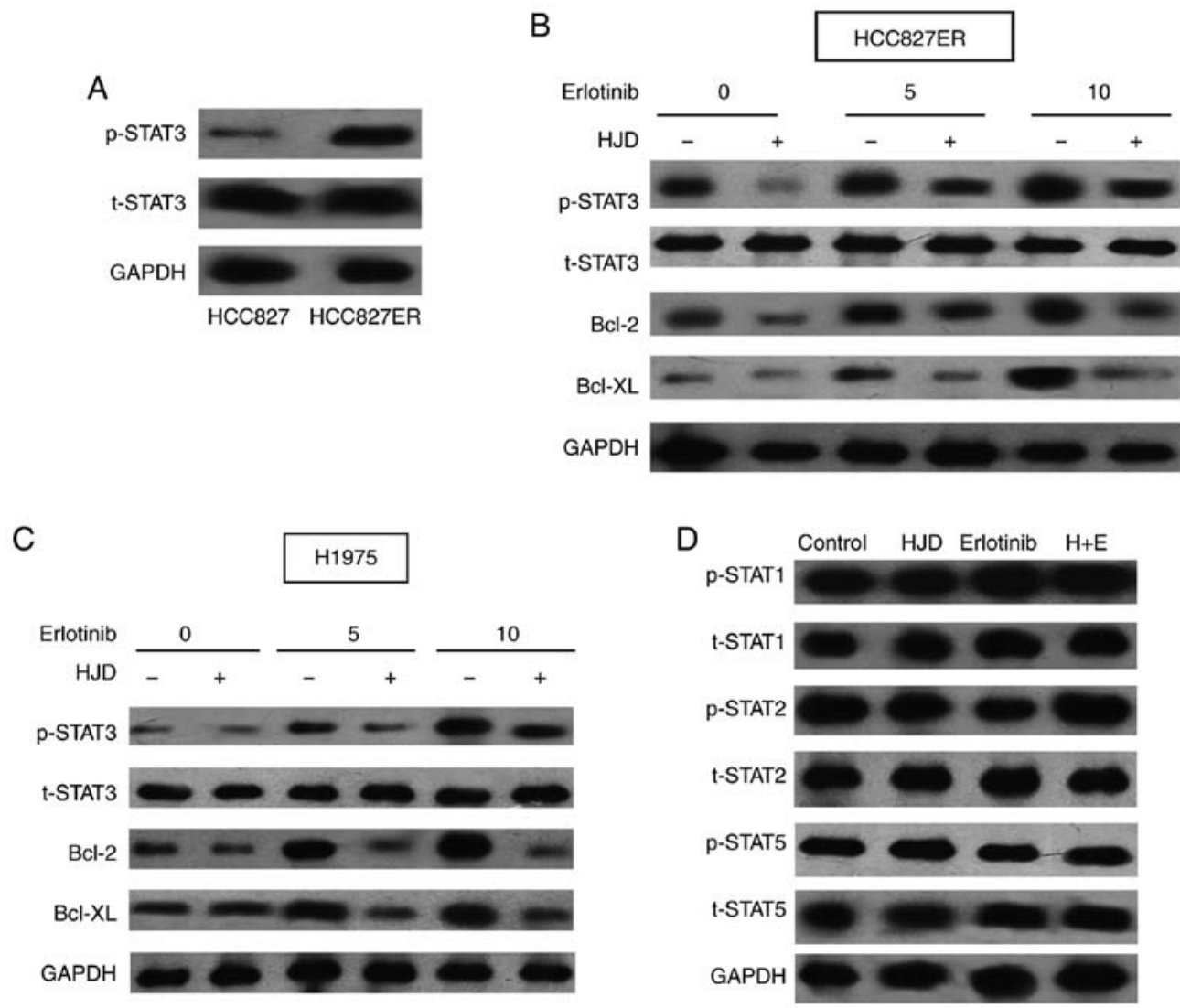

Figure 4. The effects of HJD, erlotinib, and HJD+E on the phosphorylation level of STAT3 and its downstream targets in HCC827, HCC827ER, and H1975 cells were detected by western blotting. (A) The expression of pSTAT3 and STAT3 in HCC728 and HCC827ER cells. (B and C) The expression of pSTAT3 and its downstream targets in HCC827ER and H1975 cells subjected to HJD/erlotinib alone or HJD plus erlotinib. (D) The protein levels of STATs in HCC827ER cells subjected to HJD/erlotinib alone or HJD plus erlotinib.
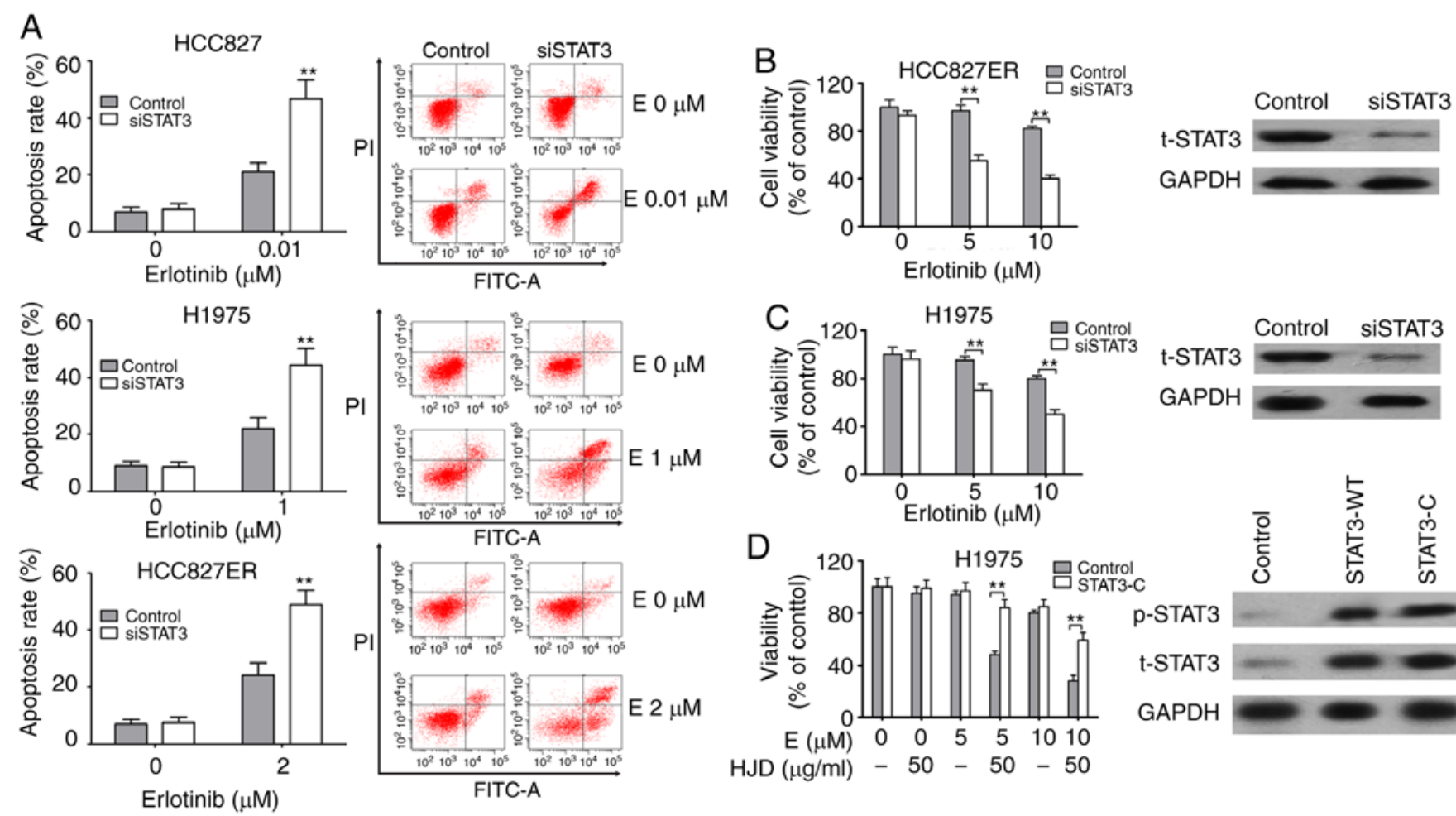

Figure 5. The effect of siSTAT3 on apoptosis induced by HJD and erlotinib combination. (A) Flow cytometry was used to detect the effect of siSTAT3 on erlotinib-induced apoptosis of HCC827, HCC827ER and H1975. ${ }^{* *} \mathrm{P}<0.01$ (vs. erlotinib). (B and C) The effect of siSTAT3 on the viability of HCC827ER and H1975 exposed to erlotinib by CCK-8 assays. ${ }^{* *} \mathrm{P}<0.01$ (vs. erlotinib). (D) The effect of STAT3 plasmid on the viability of H1975 exposed to erlotinib and/or HJD by CCK- 8 assays. ${ }^{* *} \mathrm{P}<0.01$ (vs. control). Each value represents the mean \pm SD. 
A

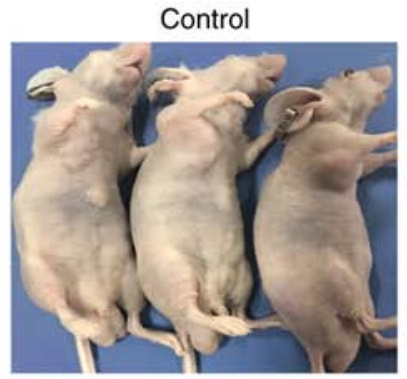

Erlotinib

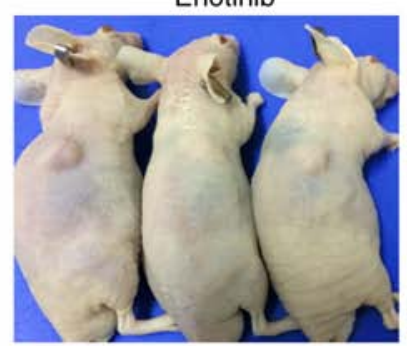

C
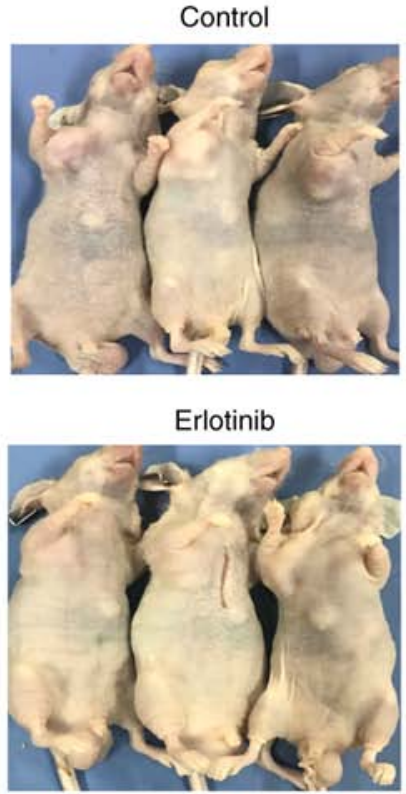

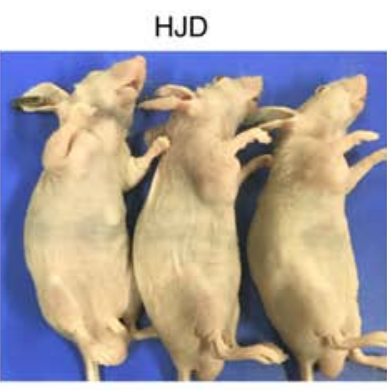

Combined

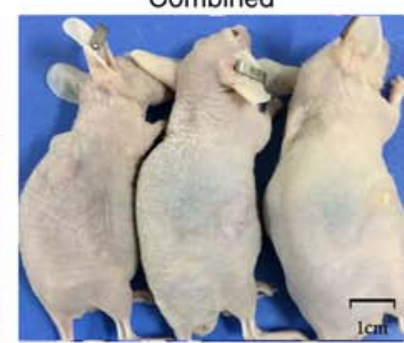

HJD

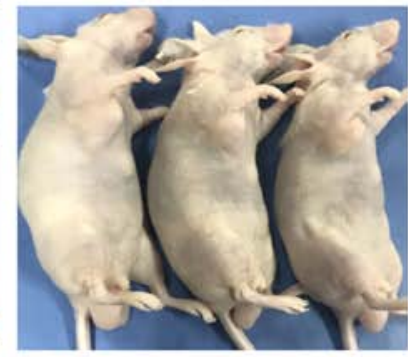

Combined

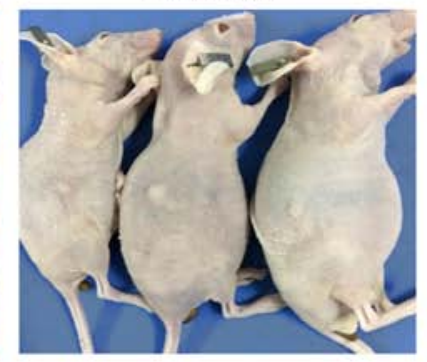

B

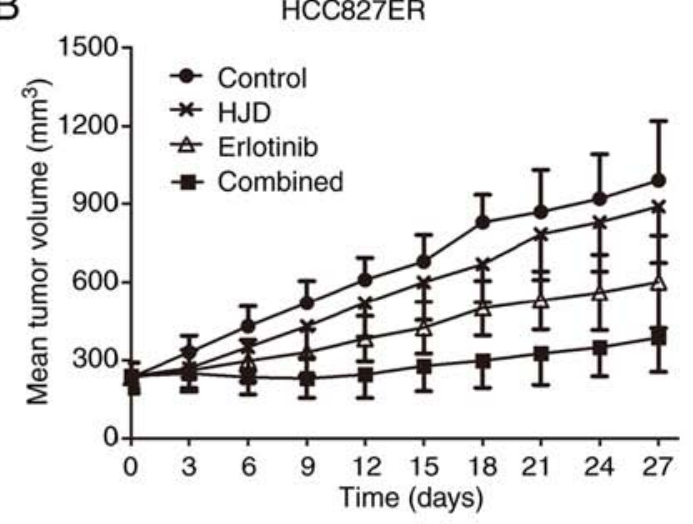

D

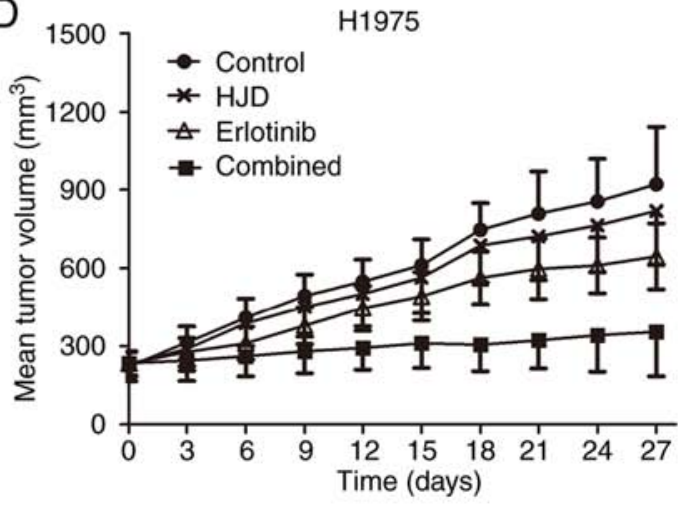

Figure 6. Combined treatment of HJD and erlotinib inhibit tumor growth in mice-bearing HCC827ER or H1975 xenografts. The nude mice (n=6) were given saline (control group), $20 \mathrm{mg} / \mathrm{kg}$ erlotinib, $50 \mathrm{mg} / \mathrm{kg}$ HJD or both, respectively. (A) Mice with representative HCC827ER tumors are shown. (B) Tumor volumes in mice-bearing HCC827ER xenografts. (C) Mice with representative H1975 tumors are shown. (D) Tumor volumes in mice-bearing H1975 xenografts. Tumor volume was recorded every 3 days. Each value represents the mean \pm SD.

on H1975 and HCC827ER cell viability (Fig. 5B and C). Furthermore, plasmids expressing constitutively activated STAT3 (STAT3-C) were employed. Overexpression of STAT3 in H1975 cells significantly inhibited HJD-mediated erlotinib sensitization (Fig. 5D).

HJD potentiates the tumor-inhibiting activity of erlotinib in vivo. Next, we evaluated whether combination therapy could alleviate erlotinib resistance in HCC827ER and H1975 xenograft nude mice. The nude mice were divided into the control, HJD, erlotinib, and HJD+erlotinib groups. After erlotinib treatment of HCC827ER xenograft, tumor growth was retarded. Although the tumor volume treated with HJD was smaller than that of the control group, there were no substantial differences. The combination of HJD with erlotinib in particular elicited an extremely strong tumor regression (Fig. 6). At the end of the experiment ( 27 days of co-treatment), tumors were barely palpable. In summary, these results indicate that erlotinib and HJD contributed to substantial tumor shrinkage of established xenografts bearing EGFR T790M mutation.

Caspase 3-positive cells were greatly increased in the co-treatment group, whereas Ki67 expression was decreased in the co-treatment group, as shown in immunohistochemical assays (Figs. 7 and 8). The levels of STAT3 and its downstream signaling target, Bcl-2, were upregulated in the erlotinib group in mice-bearing HCC827ER tumors, compared to the saline-treated group (Fig. 7). As expected, the combination of HJD and erlotinib blunted the expression of STAT3 and Bcl-2 in mice-bearing H1975 xenografts (Fig. 8). These results were also confirmed by western blot assays. For safety evaluation 
A
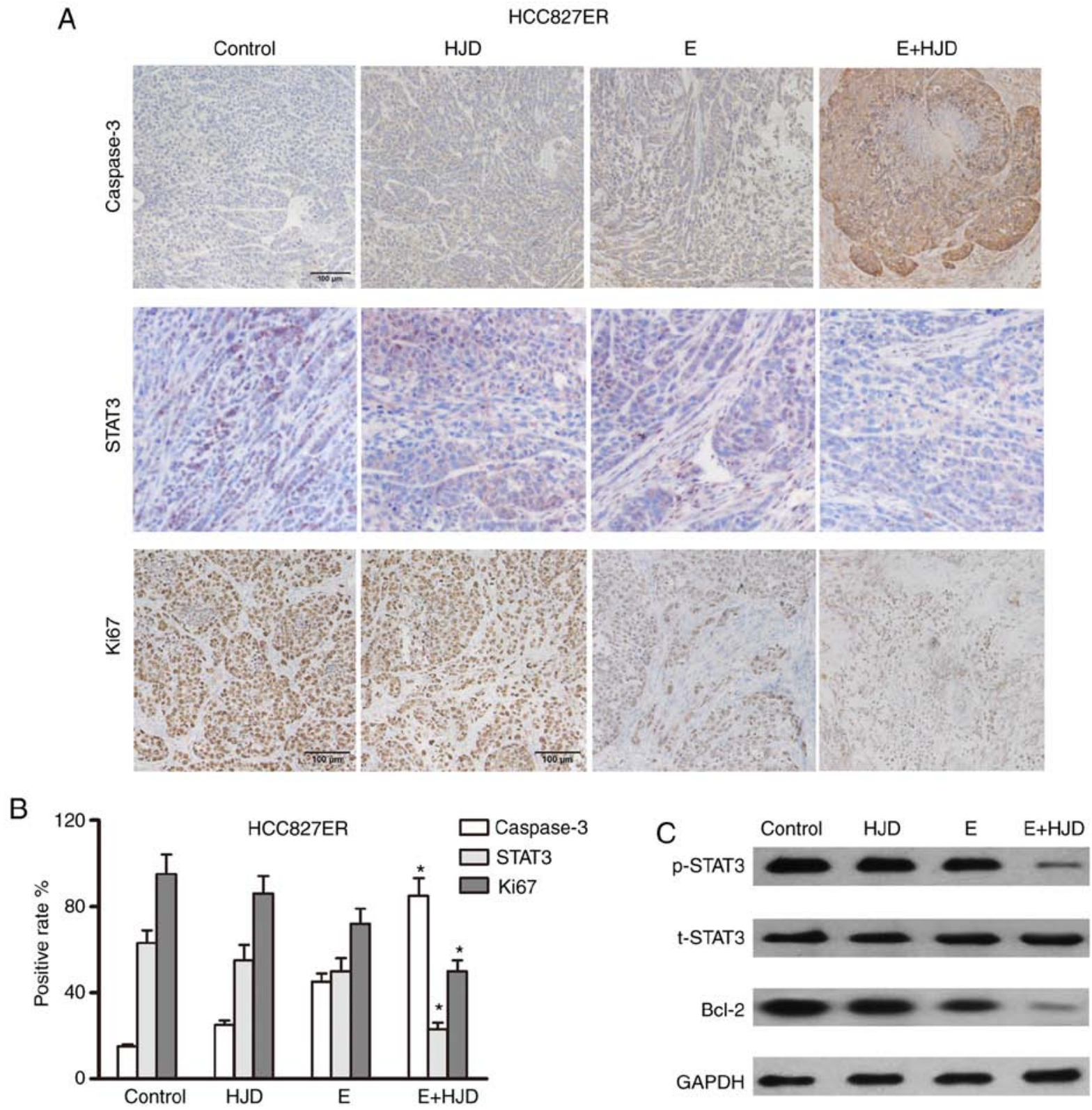

Figure 7. HJD inhibited erlotinib-induced STAT3/Bcl-2 activation in mice-bearing HCC827ER xenografts. Nude mice (n=6) were given saline (control group), $20 \mathrm{mg} / \mathrm{kg}$ erlotinib, $50 \mathrm{mg} / \mathrm{kg}$ HJD or both, respectively. (A and B) Immunohistochemistry was used to analyze protein levels of caspase 3, Ki67, and STAT3 in tumors of HCC827ER xenograft mice. The number of positive staining cells was estimated by a digital trinocular microscope. Each value represents the mean \pm SD. (C) Western blotting was used to analyze protein levels of STAT3 and Bcl-2 in tumors of HCC827ER xenograft mice. ${ }^{*} \mathrm{P}<0.05$ (vs. control).

of the combinatorial treatment, the kidneys, liver, lungs and heart of nude mice were histologically analyzed. No obvious toxicity was observed in the main organs of mice-bearing xenografts subjected to HJD plus erlotinib treatment, as shown in Figs. S2 and S3. In vivo studies suggested that HJD could overcome TKI resistance by inhibiting the STAT3 signaling pathway. The STAT3/Bcl-2 pathway is involved in the in vivo antitumor effect of HJD combined with erlotinib.

\section{Discussion}

Four members of the ERBB receptor family, namely EGFR, HER 2, HER3, and HER4 are the most studied therapeutic targets for human malignancies $(26,27)$. ErbB receptors induce EGFR activation by binding to ligands of different affinities (28). There are six major ligands for EGFR, namely epidermal growth factor, heparin-binding EGF, transforming growth factor, heregulin, amphiregulin, and betacellulin (29). In EGFR, when ligands bind to receptors, the receptors undergo conformational changes that produce homologous dimers and heterodimers (30), thereby activating downstream signaling pathways and promoting the development of cancer features, such as proliferation and survival, metastasis, and therapeutic resistance $(28,31)$. Therefore, EGFR has become a new therapeutic target for cancer. EGFR inhibitors can be divided into two categories according to their sites of action: One is EGFR-TKIs, including erlotinib, afatinib, gefitinib and osimertinib $(32,33)$. The other is extracellular EGRF-mab, such as cetuximab and panitumumab $(34,35)$. 
A
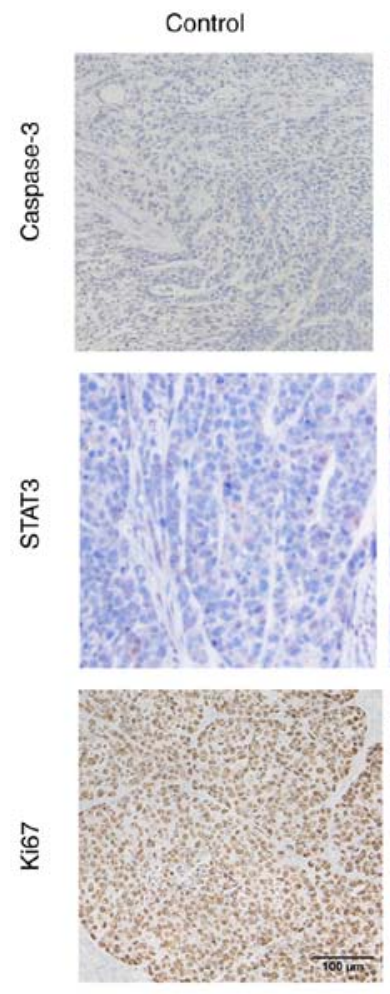

$\mathrm{H} 1975$

HJD
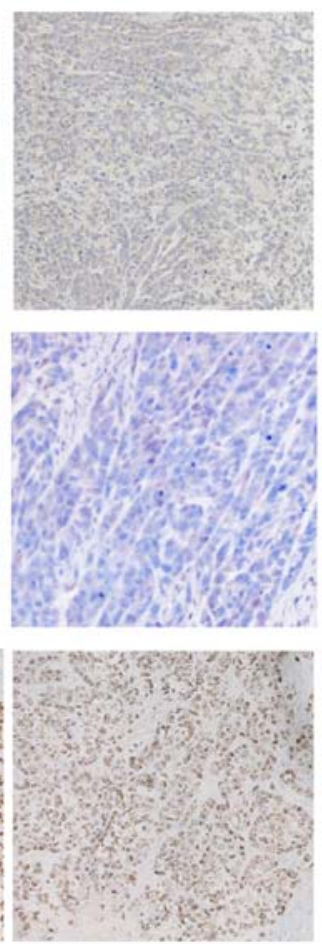

B

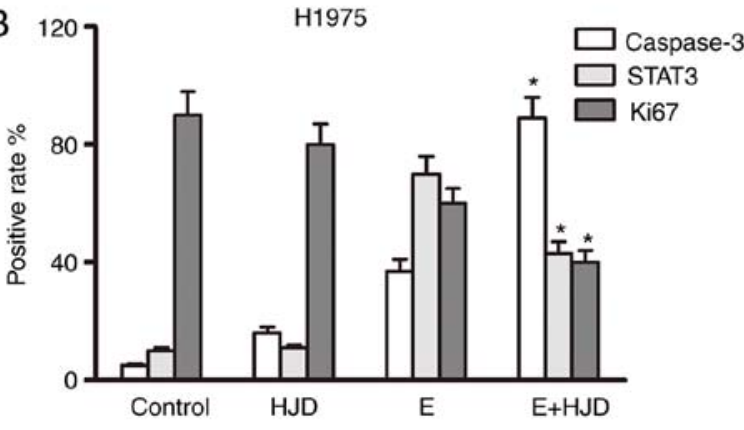

E
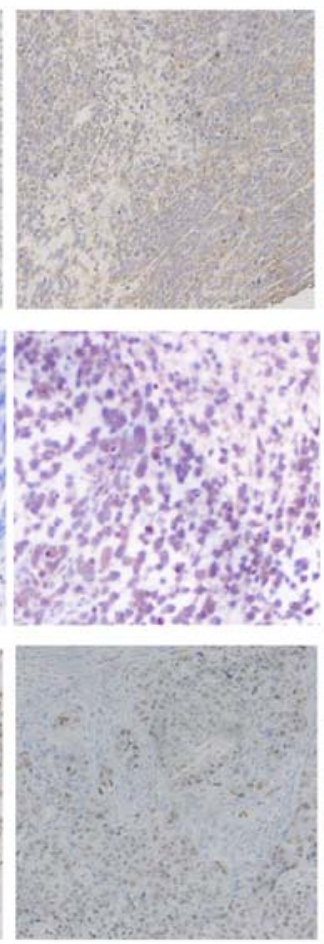

E+HJD
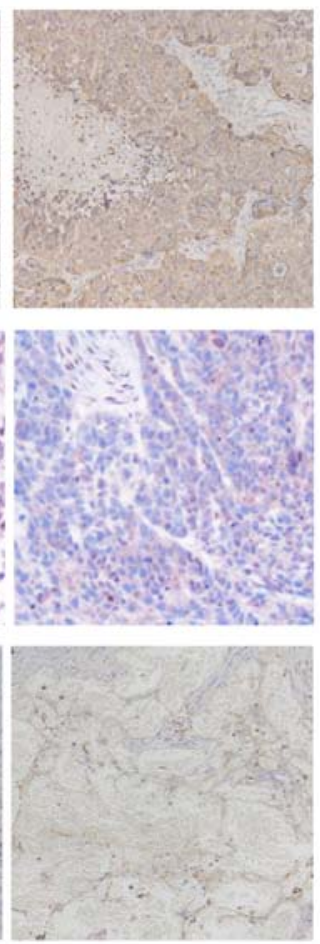

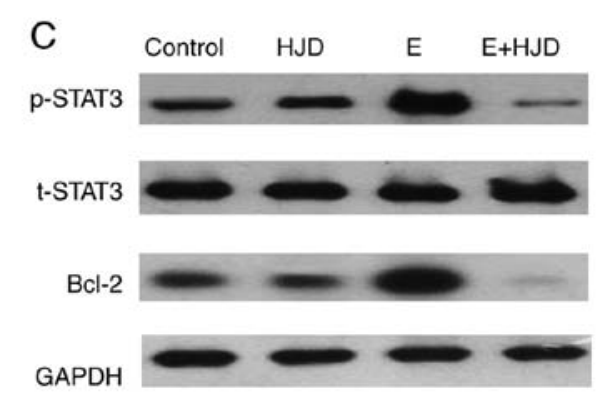

Figure 8. HJD inhibited erlotinib-induced STAT3/Bcl-2 activation in mice-bearing H1975 xenografts. Nude mice (n=6) were given saline (control group), $20 \mathrm{mg} / \mathrm{kg}$ erlotinib, $50 \mathrm{mg} / \mathrm{kg}$ HJD or both, respectively. (A and B) Immunohistochemistry was used to analyze protein levels of caspase 3, Ki67, and STAT3 in tumors of $\mathrm{H} 1975$ xenograft mice. The number of positive staining cells was estimated by an image analysis software. Each value represents the mean \pm SD (C) Western blotting was used to analyze protein levels of STAT3 and Bcl-2 in tumors of H1975 xenograft mice. * P<0.05 (vs. control).

EGFR inhibitors have shown clinical benefit for NSCLC, but less than $10 \%$ of previously treated NSCLC patients have an objective tumor response $(36,37)$ and patients develop resistance in the end. Erlotinib is an oral low-molecular-weight quinazoline-based agent, which acts as a reversible and selective kinase inhibitor of EGFR and has a better anticancer effect, less toxicity, and longer progression-free survival than chemotherapy $(38,39)$. It has been applied for NSCLC patients with activating EGFR mutations. Although erlotinib is widely used in the treatment of NSCLC, many patients also develop resistance to it, which poses a challenge in oncology. Mutation of T790M in EGFR kinase is reported to be the most common mechanism of resistance to erlotinib (40). Our experiments show that T790M mutant H1975 cells are not sensitive to erlotinib, which is consistent with previous findings (41). The combination of HJD and erlotinib could overcome drug resistance induced by the T790M mutation in primary and acquired resistance cells in vitro and in vivo, which may represent an alternative therapeutic strategy in patients with acquired resistance to EGFR-TKIs.

The majority of components of HJD are known to influence critical processes of angiogenesis and metastasis by affecting numerous effector molecules. Findings of previous studies have shown that the main component of HJD has antitumor effects $(42,43)$. The inhibitory effect of HJD on cancer cells has been confirmed in human myeloma cells, and its active compounds, baicalin and wogonin, are related to the inhibition of cancer cell growth, cell cycle arrest, and apoptosis $(44,45)$. Results of this study revealed that HJD efficaciously increased the sensitivity of NSCLC cells to erlotinib. A synergistic effect was found in H1975 and HCC827ER cells. The combination displayed an additive effect on A549 cells bearing wild-type EGFR. In accordance with previous research $(46,47)$, both HCC827ER and H1975 cells harbor the T790M mutation and exhibit a higher level of EGFR activity than A549 cells expressing wild-type EGFR (data not shown). It is widely 
acknowledged that T790M mutation is a critical factor for erlotinib resistance. This discrepancy between cells harboring wild-type or mutant EGFR possibly ascribe to variant cellular dependency for survival to EGFR pathways (48). The inhibitory effect of HJD+E combination surmounted the threshold that cancer cells could bear, and induced more lethal damage to cells with mutant EGFR.

STAT3 are important proto-carcinoma transcription factors in a variety of cancers (49-51). STAT3 activation has been reported in approximately $50 \%$ of NSCLC primary tumors and lung cancer-derived cell lines, which is one of the most important carcinogenic factors in NSCLC $(52,53)$. STAT3 activation induces the transcription of a variety of genes (such as $c$-myc, cyclin $D 1, b c l$-2) that play a key role in the pathogenesis of lung cancer (54). Previous findings have shown that EGFR mutations activate STAT3 (55). In addition, it has been shown that abnormal activation of STAT3 can be observed in a variety of drug-resistant cells, and inhibition of STAT3 activation can alleviate drug resistance $(14,56,57)$. Erlotinib therapy resulted in the feedback activation of STAT3 in H1975 cells, and we later transfected HCC827, HCC827ER and H1975 cells with siRNAs. siSTAT3 significantly inhibited STAT3 and enhanced drug response. The result proved that STAT3 caused erlotinib resistance, in accordance with previous findings (58). In our study, HJD promoted erlotinib to enhance caspase 3 activation and tumor cell apoptosis. The combination of HJD and erlotinib blunted the expression of STAT3 and Bcl-2, suggesting HJD can inhibit the STAT3 signaling pathway to overcome TKI resistance.

In our study, HJD significantly alleviates resistance by regulating the $\mathrm{STAT} 3 / \mathrm{Bcl}-2$ signaling pathway. In addition, the results suggest that inhibition of the STAT3/Bcl-2 pathway contributed greatly to the abolishment of acquired resistance to erlotinib. Combination therapy of HJD and erlotinib offers a promising prospect for enhancing drug response and extending survival in patients with lung cancer.

\section{Acknowledgements}

Not applicable.

\section{Funding}

Funding was provided by the Medical innovation team of Jiangsu province (CXTDB2017003), Jiangsu Province's colleges and universities (integration of Chinese and Western medicine).

\section{Availability of data and materials}

The datasets used during the present study are available from the corresponding author upon reasonable request.

\section{Authors' contributions}

RZ and LW designed and performed experiments. ZX and BL analyzed the data and wrote the manuscript. XZ and QN also performed the experiments. LZ analyzed the data. All authors read and approved the manuscript and agree to be accountable for all aspects of the research in ensuring that the accuracy or integrity of any part of the work are appropriately investigated and resolved.

\section{Ethics approval and consent to participate}

The animal experiments were approved by the ethics committee of the Affiliated Hospital of Integrated Traditional Chinese and Western Medicine (Nanjing, China).

\section{Patient consent for publication}

Not applicable.

\section{Competing interests}

The authors declare that they have no conflict of interest.

\section{References}

1. Miao S, Qiu T, Zhao Y, Wang H, Sun X, Wang Y, Xuan Y, Qin Y and Jiao W: Overexpression of S100A13 protein is associated with tumor angiogenesis and poor survival in patients with early-stage non-small cell lung cancer. Thorac Cancer 9: 1136-1144, 2018.

2. Siegel RL, Miller KD and Jemal A: Cancer statistics, 2018. CA Cancer J Clin 68: 7-30, 2018.

3. Morgant MC, Pages PB, Orsini B, Falcoz PE, Thomas PA, Barthes Fle P, Dahan M and Bernard A; Epithor project (French Society of Thoracic and Cardiovascular Surgery): Time trends in surgery for lung cancer in France from 2005 to 2012: A nationwide study. Eur Respir J 46: 1131-1139, 2015.

4. Wu AJ, Garay E, Foster A, Hsu M, Zhang Z, Chaft JE, Huang J, Rosenzweig KE and Rimner A: Definitive radiotherapy for local recurrence of NSCLC after surgery. Clin Lung Cancer 18: e161-e168, 2017.

5. Hattori A, Matsunaga T, Takamochi K, Oh S and Suzuki K: Locoregional recurrence after segmentectomy for clinicalT1aN0M0 radiologically solid non-small-cell lung carcinoma. Eur J Cardiothorac Surg 51: 518-525, 2017.

6. Mghwary AE, Gedawy EM, Kamal AM and Abuel-Maaty SM: Novel thienopyrimidine derivatives as dual EGFR and VEGFR-2 inhibitors: Design, synthesis, anticancer activity and effect on cell cycle profile. J Enzyme Inhib Med Chem 34: 838-852, 2019.

7. Reckamp KL, Frankel PH, Ruel N, Mack PC, Gitlitz BJ, Li T, Koczywas M, Gadgeel SM, Cristea MC, Belani CP, et al: Phase II trial of cabozantinib plus erlotinib in patients with advanced epidermal growth factor receptor (EGFR)-mutant non-small cell lung cancer with progressive disease on epidermal growth factor receptor tyrosine kinase inhibitor therapy: A California Cancer Consortium phase II trial (NCI 9303). Front Oncol 9: 132, 2019.

8. Yang KM, Shin IC, Park JW, Kim KS, Kim DK, Park K and Kim K: Nanoparticulation improves bioavailability of erlotinib. Drug Dev Ind Pharm 43: 1557-1565, 2017.

9. Cardona AF, Arrieta O, Zapata MI, Rojas L, Wills B, Reguart N, Karachaliou N, Carranza H, Vargas C, Otero J, et al: Acquired resistance to erlotinib in EGFR mutation-positive lung adenocarcinoma among hispanics (CLICaP). Target Oncol 12: 513-523, 2017.

10. Hu H, Miao XK, Li JY, Zhang XW, Xu JJ, Zhang JY, Zhou TX, Hu MN, Yang WL and Mou LY: YC-1 potentiates the antitumor activity of gefitinib by inhibiting HIF-1 $\alpha$ and promoting the endocytic trafficking and degradation of EGFR in gefitinib-resistant non-small-cell lung cancer cells. Eur J Pharmacol 874: 172961, 2020.

11. Gandhi J, Zhang J, Xie Y, Soh J, Shigematsu H, Zhang W, Yamamoto H, Peyton M, Girard L, Lockwood WW, et al: Alterations in genes of the EGFR signaling pathway and their relationship to EGFR tyrosine kinase inhibitor sensitivity in lung cancer cell lines. PLoS One 4: e4576, 2009.

12. Li Y, Fan S, Koo J, Yue P, Chen ZG, Owonikoko TK, Ramalingam SS, Khuri FR and Sun SY: Elevated expression of eukaryotic translation initiation factor $4 \mathrm{E}$ is associated with proliferation, invasion and acquired resistance to erlotinib in lung cancer. Cancer Biol Ther 13: 272-280, 2012. 
13. Li R, Hu Z, Sun SY, Chen ZG, Owonikoko TK, Sica GL, Ramalingam SS, Curran WJ, Khuri FR and Deng X: Niclosamide overcomes acquired resistance to erlotinib through suppression of STAT3 in non-small cell lung cancer. Mol Cancer Ther 12: 2200-2212, 2013.

14. Lee HJ, Zhuang G, Cao Y, Du P, Kim HJ and Settleman J: Drug resistance via feedback activation of Stat 3 in oncogene-addicted cancer cells. Cancer Cell 26: 207-221, 2014.

15. Lou W, Chen Y, Zhu KY, Deng H, Wu T and Wang J: Polyphyllin I overcomes EMT-associated resistance to erlotinib in lung cancer cells via IL-6/STAT3 pathway inhibition. Biol Pharm Bull 40: 1306-1313, 2017.

16. Chen G, Bao Y, Weng Q, Zhao Y, Lu X, Fu L, Chen L, Liu Z, Zhang $X$ and Liang G: Compound $15 \mathrm{c}$, a novel dual inhibitor of EGFR ${ }^{\mathrm{L} 858 \mathrm{R} / \mathrm{T} 790 \mathrm{M}}$ and FGFR1, efficiently overcomes epidermal growth factor receptor-tyrosine kinase inhibitor resistance of non-small-cell lung cancers. Front Pharmacol 10: 1533, 2020.

17. Hsu YL, Kuo PL, Tzeng TF, Sung SC, Yen MH, Lin LT and Lin CC: Huang-lian-jie-du-tang, a traditional Chinese medicine prescription, induces cell-cycle arrest and apoptosis in human liver cancer cells in vitro and in vivo. J Gastroenterol Hepatol 23: e290-e299, 2008.

18. He MY, Deng YX, Shi QZ, Zhang XJ and Lv Y: Comparative pharmacokinetic investigation on baicalin and wogonoside in type 2 diabetic and normal rats after oral administration of traditional Chinese medicine Huanglian Jiedu decoction. J Ethnopharmacol 155: 334-342, 2014.

19. Ke M, Zhang Z, Xu B, Zhao S, Ding Y, Wu X, Wu R, Lv Y and Dong J: Baicalein and baicalin promote antitumor immunity by suppressing PD-L1 expression in hepatocellular carcinoma cells. Int Immunopharmacol 75: 105824, 2019.

20. Wang HY, Yu HZ, Huang SM and Zheng YL: P53, Bcl-2 and cox-2 are involved in berberine hydrochloride-induced apoptosis of HeLa229 cells. Mol Med Rep 14: 3855-3861, 2016.

21. Zhu M, Ying J, Lin C, Wang Y, Huang K, Zhou Y and Teng H: Baicalin induces apoptotic death of human chondrosarcoma cells through mitochondrial dysfunction and downregulation of the PI3K/Akt/mTOR pathway. Planta Med 85: 360-369, 2019.

22. Wu X, Liu P, Zhang H, Li Y, Salmani JM, Wang F, Yang K, Fu R, Chen $\mathrm{Z}$ and Chen B: Wogonin as a targeted therapeutic agent for EBV (+) lymphoma cells involved in LMP1/NF- $\kappa \mathrm{B} / \mathrm{miR}-155 / \mathrm{PU} .1$ pathway. BMC Cancer 17: 147, 2017.

23. Shan F, Shao Z, Jiang S and Chen Z: Erlotinib induces the human non-small-cell lung cancer cells apoptosis via activating ROS-dependent JNK pathways. Cancer Med 5: 3166-3175, 2016

24. Ji XL and He M: Sodium cantharidate targets STAT3 and abrogates EGFR inhibitor resistance in osteosarcoma. Aging (Albany NY) 11: 5848-5863, 2019.

25. Zhang FQ, Yang WT, Duan SZ, Xia YC, Zhu RY and Chen YB: JAK2 inhibitor TG101348 overcomes erlotinib-resistance in non-small cell lung carcinoma cells with mutated EGF receptor. Oncotarget 6: 14329-14343, 2015.

26. Yarden Y and Sliwkowski MX: Untangling the ErbB signalling network. Nat Rev Mol Cell Biol 2: 127-137, 2001.

27. Citri A and Yarden Y: EGF-ERBB signalling: Towards the systems level. Nat Rev Mol Cell Biol 7: 505-516, 2006.

28. Wang Z: ErbB receptors and cancer. Methods Mol Biol 1652: $3-35,2017$

29. Carcereny E, Moran T, Capdevila L, Cros S, Vilà L, de Los Llanos Gil M, Remón J and Rosell R: The epidermal growth factor receptor (EGRF) in lung cancer. Transl Respir Med 3: 1, 2015.

30. Marmor MD, Skaria KB and Yarden Y: Signal transduction and oncogenesis by ErbB/HER receptors. Int J Radiat Oncol Biol Phys 58: 903-913, 2004.

31. Prickett TD, Agrawal NS, Wei X, Yates KE, Lin JC, Wunderlich JR, Cronin JC, Cruz P, Rosenberg SA and Samuels Y: Analysis of the tyrosine kinome in melanoma reveals recurrent mutations in ERBB4. Nat Genet 41: 1127-1132, 2009.

32. Skoulidis F and Papadimitrakopoulou VA: Targeting the gatekeeper: Osimertinib in EGFR T790M mutation-positive non-small cell lung cancer. Clin Cancer Res 23: 618-622, 2017.

33. Wu P, Nielsen TE and Clausen MH: FDA-approved small-molecule kinase inhibitors. Trends Pharmacol Sci 36: 422-439, 2015

34. Agustoni F, Suda K, Yu H, Ren S, Rivard CJ, Ellison K, Caldwell C Jr, Rozeboom L, Brovsky K and Hirsch FR: EGFR-directed monoclonal antibodies in combination with chemotherapy for treatment of non-small-cell lung cancer: An updated review of clinical trials and new perspectives in biomarkers analysis. Cancer Treat Rev 72: 15-27, 2019.
35. Russo A, Franchina T, Ricciardi GR, Picone A, Ferraro G, Zanghì M, Toscano G, Giordano A and Adamo V: A decade of EGFR inhibition in EGFR-mutated non small cell lung cancer (NSCLC): Old successes and future perspectives. Oncotarget 6: 26814-26825, 2015.

36. Thatcher N, Chang A, Parikh P, Rodrigues Pereira J, Ciuleanu T, von Pawel J, Thongprasert S, Tan EH, Pemberton K, Archer V and Carroll K: Gefitinib plus best supportive care in previously treated patients with refractory advanced non-small-cell lung cancer: Results from a randomised, placebo-controlled, multicentre study (Iressa Survival Evaluation in Lung Cancer). Lancet 366: 1527-1537, 2005.

37. Shepherd FA, Rodrigues Pereira J, Ciuleanu T, Tan EH, Hirsh V, Thongprasert S, Campos D, Maoleekoonpiroj S, Smylie M, Martins R, et al: Erlotinib in previously treated non-small-cell lung cancer. N Engl J Med 353: 123-132, 2005.

38. Rosell R, Carcereny E, Gervais R, Vergnenegre A, Massuti B, Felip E,Palmero R, Garcia-Gomez R, Pallares C, Sanchez JM, et al: Erlotinib versus standard chemotherapy as first-line treatment for European patients with advanced EGFR mutation-positive non-small-cell lung cancer (EURTAC): A multicentre, open-label, randomised phase 3 trial. Lancet Oncol 13: 239-246, 2012.

39. Zhou C, Wu YL, Chen G, Feng J, Liu XQ, Wang C, Zhang S, Wang J, Zhou S, Ren S, et al: Erlotinib versus chemotherapy as first-line treatment for patients with advanced EGFR mutation-positive non-small-cell lung cancer (OPTIMAL, CTONG-0802): A multicentre, open-label, randomised, phase 3 study. Lancet Oncol 12: 735-742, 2011.

40. Li YL, Pan YN, Wu WJ, Mao SY, Sun J, Zhao YM, Dong JY, Zhang DY, Pan JP, Zhang C and Lin NM: Evodiamine induces apoptosis and enhances apoptotic effects of erlotinib in wild-type EGFR NSCLC cells via S6K1-mediated Mcl-1 inhibition. Med Oncol 33: 16, 2016.

41. Yang K, Chen Y, Zhou J, Ma L, Shan Y, Cheng X, Wang Y, Zhang Z, Ji X, Chen L, et al: Ursolic acid promotes apoptosis and mediates transcriptional suppression of CT45A2 gene expression in non-small-cell lung carcinoma harbouring EGFR T790M mutations. Br J Pharmacol 176: 4609-4624, 2019.

42. Ma Z, Otsuyama K, Liu S, Abroun S, Ishikawa H, Tsuyama N, Obata M, Li FJ, Zheng X, Maki Y, et al: Baicalein, a component of Scutellaria radix from Huang-Lian-Jie-Du-Tang (HLJDT), leads to suppression of proliferation and induction of apoptosis in human myeloma cells. Blood 105: 3312-3318, 2005.

43. Lee WR, Shen SC, Lin HY, Hou WC, Yang LL and Chen YC: Wogonin and fisetin induce apoptosis in human promyeloleukemic cells, accompanied by a decrease of reactive oxygen species, and activation of caspase 3 and $\mathrm{Ca}(2+)$-dependent endonuclease. Biochem Pharmacol 63: 225-236, 2002.

44. Bonham M, Posakony J, Coleman I, Montgomery B, Simon J and Nelson PS: Characterization of chemical constituents in Scutellaria baicalensis with antiandrogenic and growth-inhibitory activities toward prostate carcinoma. Clin Cancer Res 11: 3905-3914, 2005 .

45. Himeji M, Ohtsuki T, Fukazawa H, Tanaka M, Yazaki S, Ui S, Nishio K, Yamamoto H, Tasaka K and Mimura A: Difference of growth-inhibitory effect of Scutellaria baicalensis-producing flavonoid wogonin among human cancer cells and normal diploid cell. Cancer Lett 245: 269-274, 2007.

46. Bosse K, Haneder S, Arlt C, Ihling CH, Seufferlein T and Sinz A: Mass spectrometry-based secretome analysis of non-small cell lung cancer cell lines. Proteomics 16: 2801-2814, 2016.

47. Serizawa M, Murakami H, Watanabe M, Takahashi T, Yamamoto N and Koh Y: Peroxisome proliferator-activated receptor $\mathrm{Y}$ agonist efatutazone impairs transforming growth factor $\beta 2$-induced motility of epidermal growth factor receptor tyrosine kinase inhibitor-resistant lung cancer cells. Cancer Sci 105: 683-689, 2014.

48. Song J, Zhong R, Huang H, Zhang Z, Ding D, Yan H, Sun E and Jia X: Combined treatment with Epimedium koreanum Nakai extract and gefitinib overcomes drug resistance caused by T790M mutation in non-small cell lung cancer cells. Nutr Cancer 66: 682-689, 2014.

49. Chen Y, Zeng Z and Lu Y: Is mIndy a mediator of energy metabolism reprogramming in hepatocellular carcinoma induced by interleukin-6/signal transducer and activator of transcription 3 signaling? Hepatology 67: 451-452, 2018.

50. Liu X, Wei W, Li X, Shen P, Ju D, Wang Z, Zhang R, Yang F, Chen C, Cao K, et al: BMI1 and MEL18 promote colitis-associated cancer in mice via REG3B and STAT3. Gastroenterology 153: 1607-1620, 2017. 
51. Atsaves V, Tsesmetzis N, Chioureas D, Kis L, Leventaki V, Drakos E, Panaretakis T, Grander D, Medeiros LJ, Young KH and Rassidakis GZ: PD-L1 is commonly expressed and transcriptionally regulated by STAT3 and MYC in ALK-negative anaplastic large-cell lymphoma. Leukemia 31: 1633-1637, 2017.

52. Yamaguchi M, Suzuki R, Kwong YL, Kim WS, Hasegawa Y, Izutsu K, Suzumiya J, Okamura T, Nakamura S, Kawa K and Oshimi K: Phase I study of dexamethasone, methotrexate, ifosfamide, L-asparaginase, and etoposide (SMILE) chemotherapy for advanced-stage, relapsed or refractory extranodal natural killer (NK)/T-cell lymphoma and leukemia. Cancer Sci 99: 1016-1020, 2008.

53. Chen W, Zheng R, Baade PD, Zhang S, Zeng H, Bray F, Jemal A, Yu XQ and He J: Cancer statistics in China, 2015. CA Cancer J Clin 66: 115-132, 2016.

54. Xiao Q, Zheng F, Wu J, Tang Q, Wang W and Hann SS: Activation of ERK and mutual regulation of Stat 3 and SP1 contribute to inhibition of PDK1 expression by atractylenolide-1 in human lung cancer cells. Cell Physiol Biochem 43: 2353-2366, 2017.
55. Sordella R, Bell DW, Haber DA and Settleman J: Gefitinib-sensitizing EGFR mutations in lung cancer activate anti-apoptotic pathways. Science 305: 1163-1167, 2004.

56. Van Schaeybroeck S, Kalimutho M, Dunne PD, Carson R, Allen W, Jithesh PV, Redmond KL, Sasazuki T, Shirasawa S, Blayney J, et al: ADAM17-dependent c-MET-STAT3 signaling mediates resistance to MEK inhibitors in KRAS mutant colorectal cancer. Cell Rep 7: 1940-1955, 2014.

57. Li G, Zhao L, Li W, Fan K, Qian W, Hou S, Wang H, Dai J, Wei H and Guo Y: Feedback activation of STAT3 mediates trastuzumab resistance via upregulation of MUC1 and MUC4 expression. Oncotarget 5: 8317-8329, 2014.

58. Zhao C, Li H, Lin HJ, Yang S, Lin J and Liang G: Feedback activation of STAT3 as a cancer drug-resistance mechanism. Trends Pharmacol Sci 37: 47-61, 2016.

This work is licensed under a Creative Commons Attribution-NonCommercial-NoDerivatives 4.0 International (CC BY-NC-ND 4.0) License. 